\title{
WFS1 variants in Finnish patients with diabetes mellitus, sensorineural hearing impairment or optic atrophy, and in suicide victims
}

\author{
Laura Kytövuori $^{1,2,3}$, Allan Seppänen ${ }^{1,2,3}$, Mika H Martikainen ${ }^{4,5}$, Jukka S Moilanen ${ }^{6,7}$, Seija Kamppari ${ }^{8}$, \\ Terttu Särkioja ${ }^{9}$, Anne M Remes ${ }^{10,11}$, Pirkko Räsänen ${ }^{12}$, Tapani Rönnemaa ${ }^{13,14}$ and Kari Majamaa ${ }^{1,2,3}$
}

Mutations in the wolframin gene, WFS1, cause Wolfram syndrome, a rare recessive neurodegenerative disorder. The clinical features include early-onset bilateral optic atrophy (OA), diabetes mellitus (DM), diabetes insipidus, hearing impairment, urinary tract abnormalities and psychiatric illness, and, furthermore, WFS1 variants appear to be associated with non-syndromic DM and hearing impairment. Variation of WFS1 was investigated in Finnish subjects consisting 182 patients with DM, 117 patients with sensorineural hearing impairment (SNHI) and 44 patients with $\mathrm{OA}$, and in 95 suicide victims. Twenty-two variants were found in the coding region of WFS1, including three novel nonsynonymous variants. The frequency of the $\mathrm{p}$.[His456] allele was significantly higher in the patients with SNHI (11.5\%; corrected $\boldsymbol{P}=0.00008)$, DM (6.6\%; corrected $\boldsymbol{P}=0.036)$ or OA $(9.1 \%$; corrected $\boldsymbol{P}=\mathbf{0 . 0 4 3}$ ) than that in the 285 controls (3.3\%). The frequency of the p.[His611] allele was $55.8 \%$ in the patients with DM being higher than that in the controls (47\%; corrected $P=0.039)$. The frequencies of p.[His456] and p.[His611] were similarly increased in an independent group of patients with DM $(N=299)$. The results support previous findings that genetic variation of WFS1 contributes to the risk of DM and SNHI.

Journal of Human Genetics (2013) 58, 495-500; doi:10.1038/jhg.2013.29; published online 18 April 2013

Keywords: endocrine system diseases; hearing disorders; nervous system diseases; neurodegenerative diseases

\section{INTRODUCTION}

Wolfram syndrome (WS) (OMIM 222300) is a rare neurodegenerative disorder, ${ }^{1}$ also known as DIDMOAD (diabetes insipidus, juvenile diabetes mellitus (DM), early-onset optic atrophy (OA) and deafness). Besides the symptoms included in the acronym, the patients may have other neurological ${ }^{2}$ and psychiatric symptoms, ${ }^{3}$ such as paranoid delusions, psychotic behavior and suicide attempts. The estimated prevalence of WS is $1 / 770000$ in the United Kingdom. ${ }^{4}$

WS is inherited as an autosomal recessive disorder. ${ }^{5}$ The gene involved, wolframin gene (WFS1), encodes wolframin, an 890-aminoacid transmembrane protein of the endoplasmic reticulum. ${ }^{6-8}$ The protein is expressed ubiquitously and it is most abundant in the heart, pancreas, brain and muscle. ${ }^{6,9}$ Wolframin participates in cellular calcium homeostasis. ${ }^{10}$ Furthermore, it has a role in the signaling network of endoplasmic reticulum stress, ${ }^{11}$ and suppression of WFS1 has been shown to lead to endoplasmic reticulum stress in pancreatic $\beta$-cells. ${ }^{12}$
In rats, wolframin participates in the regulation of emotional behavior $^{13}$ and it may be a biomarker of post-traumatic stress. ${ }^{14}$ Disruption of WFS1 leads to difficulties in adaptation to stressful environment in mice ${ }^{15}$ and can cause progressive $\beta$-cell loss and impaired glucose homeostasis. ${ }^{12}$ In addition, it has been shown that the symptoms of WFS1 knockout mice partly resemble a depression disorder. $^{16}$

Mutations in the WFS1 gene cause a loss of function of wolframin ${ }^{6,7,17}$ by cellular depletion of the protein. ${ }^{18}$ Patients with WS are homozygous or compound heterozygotes ${ }^{17}$ with respect to these mutations, while heterozygotes have an increased risk to psychiatric hospitalization, ${ }^{19}$ and an increased risk of DM and of hearing loss. ${ }^{20}$ Indeed, some nonsynonymous variants and intronic polymorphisms in WFS1 have shown a significant association with type II DM in several studies, ${ }^{21-26}$ and association has been found also in the case of type I DM. ${ }^{27}$ Many variants have been associated

${ }^{1}$ Department of Clinical Medicine, Neurology, University of Oulu, Oulu, Finland; ${ }^{2}$ Department of Neurology, Oulu University Hospital, Oulu, Finland; ${ }^{3} \mathrm{Clinical}$ Research Center, Oulu University Hospital, Oulu, Finland; ${ }^{4}$ Department of Neurology, University of Turku, Turku, Finland; ${ }^{5}$ Department of Neurology, Turku University Hospital, Turku, Finland; ${ }^{6}$ Department of Clinical Medicine, Clinical Genetics, University of Oulu, Oulu, Finland; ${ }^{7}$ Department of Clinical Genetics, Oulu University Hospital, Oulu, Finland; ${ }^{8}$ Department of Clinical Medicine, Otorhinolaryngology, University of Oulu, Oulu, Finland; ${ }^{9}$ National Institute for Health and Welfare, Oulu, Finland; ${ }^{10}$ Institute of Clinical Medicine, Department of Neurology, University of Eastern Finland, Kuopio, Finland; ${ }^{11}$ Department of Neurology, Kuopio University Hospital, Kuopio, Finland; ${ }^{12}$ Department of Clinical Medicine, Psychiatry, University of Oulu, Oulu, Finland; ${ }^{13}$ Department of Internal Medicine, University of Turku, Turku, Finland and ${ }^{14}$ Department of Internal Medicine, Turku University Hospital, Turku, Finland

Correspondence: Professor K Majamaa, Department of Clinical Medicine, Neurology, University of Oulu, PO Box 5000, FIN-90014 Oulu, Finland.

E-mail: kari.majamaa@oulu.fi

Received 6 September 2012; revised 2 January 2013; accepted 26 March 2013; published online 18 April 2013 
with hearing loss as well. ${ }^{20,22,28-31}$ Some variants have been associated with suicidal behavior or severe psychiatric disorders. ${ }^{32-35}$

In the present study we have investigated population variation in WFS1 in 343 Finnish patients with DM, sensorineural hearing impairment (SNHI) or OA, in 95 suicide victims (SVS), used as an approximation to psychiatric disorders, and in 285 healthy controls. The patients were ascertained in a defined population in northern Finland. In addition, some of the findings were replicated in an independent group of 299 patients with DM from southwestern Finland.

\section{SUBJECTS AND METHODS}

\section{Subjects}

The subjects included 182 patients with DM whose insulin treatment had been started between the ages 20 and 45 years, and who reported a family history with respect to any combination of DM, hearing loss or epilepsy in first- or second-degree relatives. ${ }^{36}$ Furthermore, the subjects included 117 patients with SNHI with reported family history ${ }^{37}$ and 44 patients with OA of unknown etiology, ${ }^{38}$ and also included 95 SVs who were under 65 years of age. Thirtyfive of the SVs had a diagnosis of psychiatric disorder. The permission for investigation of the SVs has been granted by the National Authority for Medicolegal Affairs of Finland. The controls consisted of 285 healthy volunteers free from the previously mentioned symptoms. All the subjects were residents of northern Finland. The controls were recruited from the three neighboring provinces: Northern Ostrobothnia, Kainuu and Northern Savo.

An independent group of patients $(N=299)$ with $\mathrm{DM}^{39}$ and with a family history defined as described above were screened for two variants that were detected in the primary analysis. The patients were residents of the province of Southwestern Finland.

\section{Molecular methods}

DNA was purified from blood by using QIAamp DNA Blood Mini Kit (QIAGEN, Hilden, Germany) or the standard SDS-proteinase K extraction with Phase Lock Gel (VWR International LLC, Radnor, PA, USA) from samples of the SVs. The PCR reaction was carried out with 14 separate primer pairs. Exon 8 was amplified with eight overlapping primer pairs because of its large size. The primer sequences and the conditions of amplification reactions are available on request.

Ten fragments covering five of the seven coding exons of the WFS1 gene and part of exon 8 (amino acids from 457 to 756 ) were analyzed by using conformation-sensitive gel electrophoresis ${ }^{40}$ (Figure 1). In short, amplified DNA fragments were allowed to form duplexes with themselves and with amplified control DNA fragments in a denaturating and reannealing cycle. Heteroduplexes differ from homoduplexes in mobility on a mildly denaturating gel. ${ }^{40}$ Fragments with a known nucleotide sequence were used as controls. The beginning of exon 8 (amino acids from 288 to 456) was sequenced entirely. Three nucleotide changes were screened by restriction fragment analysis by using FastDigest restriction endonucleases (Thermo Fisher Scientific, Waltham, MA, USA). These changes included synonymous polymorphism rs 1801213 in exon 6 , which was analyzed using restriction fragment analysis with SsiI, and two nonsynonymous nucleotide changes rs35932623 and rs71532874 in exon 8, which were analyzed using HhaI and TaaI, respectively. In addition, all the variations that were found using conformation-sensitive gel electrophoresis or restriction fragment length polymorphism was confirmed by sequencing from each reamplified sample.

\section{Statistical analyses}

Departures from Hardy-Weinberg equilibrium ${ }^{41}$ as well as the differences in allele frequencies between the cases and controls $^{42}$ were calculated using the Arlequin 3.5.1.2 software. ${ }^{43}$ Haplotypes were inferred and the estimated phase data was created with the ELB algorithm in the Arlequin software. In the case of each variant, four pairwise comparisons between the patient groups and controls were performed and then corrected for multiple testing by using Benjamini and Hochberg false discovery rate. ${ }^{44}$ For all pairwise comparisons, corrected $P$-values are shown throughout. IBM SPSS Statistics 19 (IBM, New York, NY, USA) was used to calculate adjusted residuals to investigate which cells cause the difference in the allele level. Adjusted residuals were considered significant $(P<0.05)$, if the value was $<-1.96$ or $>1.96 .{ }^{45}$ The comparisons between the patients' genotype and positive first-degree family history of similar symptoms were calculated using Pearson's $\chi^{2}$-test or Fisher's exact test.

\section{Bioinformatics}

The variants were named according to the recommendations of the HGVS (Human Genome Variation Society; www.hgvs.org). Nucleotides were numbered according to the reference sequence NM_006005.3 and amino acids according to the reference protein NP_005996.2 (GeneID 7466, GenBank).

Pathogenicity of the variants was predicted by using four algorithms: PolyPhen-2, ${ }^{46}$ SIFT, ${ }^{47}$ SNAP $^{48}$ and MutationTaster. ${ }^{49}$ A variant was considered a pathogenic one, if all the four predictions were against neutrality. If three of the four predictions were against neutrality, the variant was considered

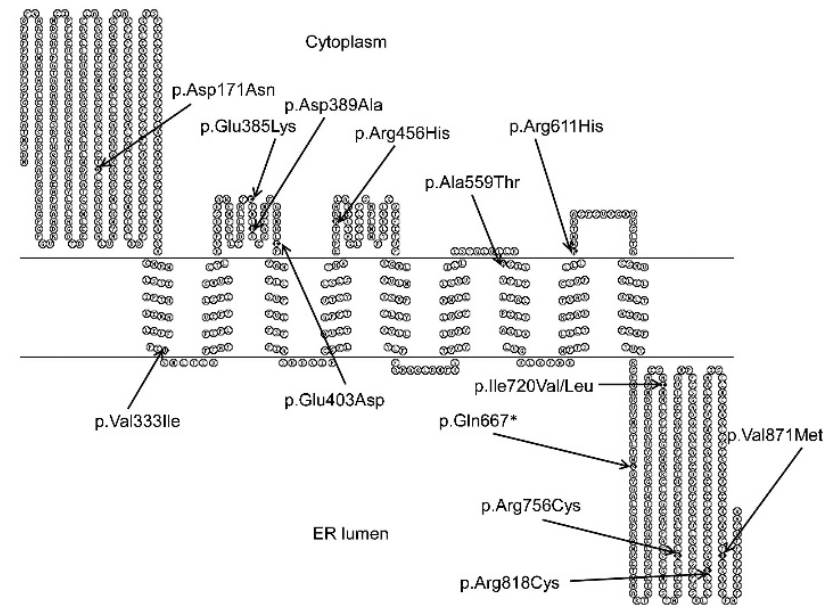

Figure 1 Coding exons of WFS 1 and exon location of identified variants. Method of sequence analysis is shown by color code. White, regions investigated by using conformation-sensitive gel electrophoresis; grey, direct sequencing; black, selected variants investigated by using restriction fragment length polymorphism. Bold font, novel variants found in this study. HGVS names are shown for nonsynonymous variants and for novel intronic variant. Rs-code is shown for synonymous and intronic variants.
Figure 2 Structure of the wolframin protein and its membrane orientation. Positions of the 13 nonsynonymous variants and one nonsense variant found in Finnish subjects are shown. Transmembrane helices encompass the amino acids 311-333, 340-362, 405-422, 429-451, 493-515, $527-549,559-581,588-610$ and 630-652. The figure was generated using TOPO2 (Johns SJ, TOPO2, http://www.sacs.ucsf.edu/TOPO2/). 
to be possibly pathogenic. Multiple sequence alignment was done by using Clustal Omega. ${ }^{50,51}$

Transmembrane segments of wolframin were predicted by using TMHMM v. 2.0. ${ }^{52}$ The figure of the protein structure (Figure 2) was drawn with TOPO2 (Johns SJ, TOPO2, Transmembrane protein display software, http://www. sacs.ucsf.edu/TOPO2/, date accessed: August 2012).

\section{RESULTS}

Genetic variation in WFS1 in Finnish patients

We detected 22 different variants in the coding exons of the WFS1 gene among the 438 subjects and 285 controls from northern Finland. The variants included 13 nonsynonymous, 1 nonsense and 8 synonymous variants. Three of the nonsynonymous variants were novel. In the intronic region we found one new polymorphism and several known changes.

The p.[His456] and p.[His611] alleles were associated with one or more of the clinical conditions (Table 1). Before corrections for multiple testing, four other variants suggested an association with $\mathrm{DM}$, one with SNHI and DM, and a novel intronic insertion suggested an association with OA. All these variants were present also in the controls, whereas seven rare variants were detected in the patients only (Table 2). Two of the rare variants were novel nonsynonymous changes, including p.Asp389Ala and p.Glu403Asp.

Furthermore, we detected seven variants that were present in the patients and controls, but that were not associated with the clinical phenotype (Table 3), and four variants that were present only in the controls, including a novel nonsynonymous variant c.511G $>$ A leading to p.Asp171Asn, a synonymous variant in exon 8, rs71539668, and two intronic variants, rs4688990 and rs71524379.

Differences in the frequencies of the WFS1 alleles between patients and controls

Global test of differentiation among sample revealed that allele frequencies differed between groups with respect to the p.Arg456His variant $(P<0.000005)$ and the p.Arg611His variant $(P=0.044)$. The frequency of the p.[His456] allele was 3.3\% (95\% confidence interval (CI), 2.1-5.2\%) in the controls, whereas the allele frequency was $6.6 \%$
(95\% CI, 4.4-9.7\%) in patients with DM ( $P=0.036$ for pairwise difference), 9.1\% (95\% CI, 4.5-17.2\%) in patients with OA ( $P=0.043$ for pairwise difference) and $11.5 \%(95 \% \mathrm{CI}, 8.0-16.3 \%)$ in the patients with SNHI $(P=0.00008$ for pairwise difference). The frequency of the p.[His611] allele was $55.8 \%(95 \% \mathrm{CI}, 50.6-60.8 \%)$ in the patients with DM and $47.0 \%$ (95\% CI, 43.0-51.1\%) in the controls $(P=0.039$ for pairwise difference). Haplotype estimation suggested that the p.Arg456His and p.Arg611His variants belong to different haplotypes.

In addition, frequencies of the p.[His456] and p.[His611] alleles were examined in an independent group of patients with DM. The frequency of the p.[His456] allele was $5.9 \% \quad(95 \% \mathrm{CI}$, 4.2-8.1\%) and that of the p.[His611] allele was 53.8\% (95\% CI, 49.8-57.8\%). The allele frequencies did not differ between the two DM groups (p.Arg456His, $P=0.85$; p.Arg611His, $P=0.76$ ).

Table 2 Rare heterozygous variants in the WFS 1 gene that were absent from controls and the pathogenicity predictions of the variants

\begin{tabular}{|c|c|c|c|c|}
\hline Rs-code & $\begin{array}{c}\text { Amino acid } \\
\text { change }\end{array}$ & $\begin{array}{c}\text { EUR MAFa } \\
\text { (Global MAF) }\end{array}$ & $\begin{array}{l}\text { Predicted } \\
\text { pathogenicity }\end{array}$ & $\begin{array}{c}\text { Number of } \\
\text { heterozygotes } \\
\text { among patients }\end{array}$ \\
\hline rs71524353 & Glu385Lys & N.D. & Possibly pathogenic & $1 \mathrm{SNHI}, 1 \mathrm{OA}$ \\
\hline c. $1166 \mathrm{~A}>\mathrm{C}$ & Asp389Ala & N.D. & Pathogenic & $1 \mathrm{SNHI}$ \\
\hline c. $1209 \mathrm{G}>\mathrm{T}$ & Glu403Asp & N.D. & Pathogenic & $1 \mathrm{DM}, 1 \mathrm{SNHI}$ \\
\hline$\overline{r s 55814513}$ & Ala559Thr & $0.004(0.001)$ & Neutral & 2 DM, 1 SV \\
\hline c. $1999 \mathrm{C}>\mathrm{T}$ & $\mathrm{G} \ln 667^{*}$ & N.D. & WS mutation ${ }^{c}$ & $1 \mathrm{SV}$ \\
\hline rs138127684 & Arg756Cys & N.D. & Pathogenic & $1 \mathrm{SNHI}, 1 \mathrm{SV}$ \\
\hline rs35932623 & Arg818Cys & $0.005(0.002)$ & Pathogenic & $2 \mathrm{DM}$ \\
\hline
\end{tabular}

Abbreviations: DM, diabetes mellitus; EUR MAF, European minimum allele frequency; Global MAF, global minimum allele frequency; N.D., not determined; OA, optic atrophy; SNHI, sensorineural hearing impairment; SV, suicide victim; WS, Wolfram syndrome.

Rs-code is shown, if available. HGVS name is shown for novel variants that are underlined. aBased on 1000 genomes database (http://www.1000genomes.org/). EUR MAF from available European populations and Global MAF from all available populations.

bBased on PolyPhen-2, SIFT, SNAP and MutationTaster predictions (3/4 predictions against neutrality considered as possibly pathogenic, $4 / 4$ predictions against neutrality considered as pathogenic).

'Recessive WS mutation.

Table 1 Genotype percentages of the associating variants in the WFS 1 gene

\begin{tabular}{|c|c|c|c|c|c|c|c|c|c|c|c|c|c|c|c|c|c|}
\hline \multirow[b]{3}{*}{ Variant } & \multirow[b]{3}{*}{$\begin{array}{c}\text { Amino acid } \\
\text { change }^{\mathrm{a}}\end{array}$} & \multirow[b]{3}{*}{$\begin{array}{l}\text { EUR MAF- } \\
\text { (Global MAF) }\end{array}$} & \multirow{2}{*}{\multicolumn{3}{|c|}{$\begin{array}{l}\text { Controls } \\
\mathrm{N}=285\end{array}$}} & \multirow{2}{*}{\multicolumn{3}{|c|}{$\begin{array}{c}D M \\
\mathrm{~N}=182\end{array}$}} & \multirow{2}{*}{\multicolumn{3}{|c|}{$\begin{array}{c}S N H I \\
N=117\end{array}$}} & \multirow{2}{*}{\multicolumn{3}{|c|}{$\begin{array}{c}O A \\
\mathrm{~N}=44\end{array}$}} & \multirow{2}{*}{\multicolumn{3}{|c|}{$\begin{array}{c}S V \\
\mathrm{~N}=95\end{array}$}} \\
\hline & & & & & & & & & & & & & & & & & \\
\hline & & & $0 / 0$ & $0 / 1$ & $1 / 1$ & $0 / 0$ & $0 / 1$ & $1 / 1$ & $0 / 0$ & $0 / 1$ & $1 / 1$ & $0 / 0$ & $0 / 1$ & $1 / 1$ & $0 / 0$ & $0 / 1$ & $1 / 1$ \\
\hline \multicolumn{18}{|l|}{ Rs-code } \\
\hline \multicolumn{18}{|c|}{ (A) Associating variants with HW equilibrium with $\mathrm{P}$-value $<0.05$ after correction } \\
\hline $\begin{array}{l}\text { rs1801208 } \\
\text { rs734312 }\end{array}$ & $\begin{array}{l}\text { Arg456His } \\
\text { Arg611His }\end{array}$ & $\begin{array}{c}\text { N.D. } \\
0.44(0.48)\end{array}$ & $\begin{array}{l}93.7 \\
29.1\end{array}$ & $\begin{array}{r}6.0 \\
47.7\end{array}$ & $\begin{array}{r}0.4 \\
23.2\end{array}$ & $\begin{array}{l}86.8^{c} \\
18.1^{c}\end{array}$ & $\begin{array}{l}13.2^{c} \\
52.2^{c}\end{array}$ & $\begin{array}{c}O^{c} \\
29.7^{c}\end{array}$ & $\begin{array}{l}78.6^{c} \\
25.6\end{array}$ & $\begin{array}{l}19.7^{c} \\
52.1\end{array}$ & $\begin{array}{l}1.7^{c} \\
22.2\end{array}$ & $\begin{array}{l}81.8^{c} \\
15.9\end{array}$ & $\begin{array}{l}18.2^{c} \\
61.4\end{array}$ & $\begin{array}{c}0^{c} \\
22.7\end{array}$ & $\begin{array}{l}88.4 \\
31.6\end{array}$ & $\begin{array}{l}11.6 \\
47.4\end{array}$ & $\begin{array}{c}0 \\
21.1\end{array}$ \\
\hline \multicolumn{18}{|c|}{ (B) Associating variants with $\mathrm{HW}$ equilibrium with $\mathrm{P}$-value $<0.05$ before correction } \\
\hline $\begin{array}{l}\text { rs10010131 } \\
\text { rs1801213 } \\
\text { c.713-88_89dupAC }\end{array}$ & - & $\begin{array}{l}0.37(0.27) \\
0.32(0.24)\end{array}$ & $\begin{array}{l}18.6 \\
17.2 \\
99.6\end{array}$ & $\begin{array}{r}50.2 \\
49.5 \\
0.4\end{array}$ & $\begin{array}{c}31.2 \\
33.3 \\
0\end{array}$ & $\begin{array}{c}15.4^{d} \\
14.3^{d} \\
100\end{array}$ & $\begin{array}{c}42.9^{d} \\
40.1^{d} \\
0\end{array}$ & $\begin{array}{l}41.8^{d} \\
45.6^{d} \\
0\end{array}$ & $\begin{array}{l}12.0 \\
9.4^{d} \\
99.1\end{array}$ & $\begin{array}{l}51.3 \\
49.6^{d} \\
0.9\end{array}$ & $\begin{array}{l}36.8 \\
41.0^{d} \\
0\end{array}$ & $\begin{array}{l}13.6 \\
11.4 \\
95.5^{d}\end{array}$ & $\begin{array}{c}52.3 \\
54.5 \\
4.5^{d}\end{array}$ & $\begin{array}{c}34.1 \\
34.1 \\
0^{d}\end{array}$ & $\begin{array}{l}25.3 \\
18.9 \\
98.9\end{array}$ & $\begin{array}{r}47.4 \\
51.6 \\
1.1\end{array}$ & $\begin{array}{c}27.4 \\
29.5 \\
0\end{array}$ \\
\hline $\begin{array}{l}\text { rs1801212 } \\
\text { rs1801206 } \\
\text { rs1801214 }\end{array}$ & $\begin{array}{c}\text { Val333Ile } \\
\quad-\end{array}$ & $\begin{array}{l}0.28(0.14) \\
0.39(0.33) \\
\text { N.D. }\end{array}$ & $\begin{array}{l}13.7 \\
17.2 \\
17.5\end{array}$ & $\begin{array}{l}44.2 \\
51.6 \\
51.2\end{array}$ & $\begin{array}{l}42.1 \\
31.2 \\
31.2\end{array}$ & $\begin{array}{l}8.8^{d} \\
14.3^{d} \\
14.3^{d}\end{array}$ & $\begin{array}{l}39.0^{d} \\
43.4^{d} \\
44.0^{d}\end{array}$ & $\begin{array}{l}52.2^{d} \\
42.3^{d} \\
41.8^{d}\end{array}$ & $\begin{array}{r}6.8 \\
12.8 \\
13.7\end{array}$ & $\begin{array}{l}46.2 \\
53.0 \\
53.8\end{array}$ & $\begin{array}{l}47.0 \\
34.2 \\
32.5\end{array}$ & $\begin{array}{r}9.1 \\
11.4 \\
11.4\end{array}$ & $\begin{array}{l}43.2 \\
54.5 \\
54.5\end{array}$ & $\begin{array}{l}47.7 \\
34.1 \\
34.1\end{array}$ & $\begin{array}{l}14.7 \\
26.3 \\
25.3\end{array}$ & $\begin{array}{l}48.4 \\
46.3 \\
47.4\end{array}$ & $\begin{array}{l}36.8 \\
27.4 \\
27.4\end{array}$ \\
\hline
\end{tabular}

Abbreviations: DM, diabetes mellitus; EUR MAF, European minimum allele frequency; Global MAF, Global minimum allele frequency; HW, Hardy-Weinberg; N.D., not determined; OA, optic atrophy; SNHI, sensorineural hearing impairment; SV, suicide victim; 0/0, homozygote with respect to the reference allele; 0/1, heterozygote with respect to the variant; $1 / 1$ homozygote with respect to the variant.

Rs-code is shown, if available. HGVS name is shown for novel variants that are underlined.

a None of the three nonsynonymous variants were predicted as pathogenic or possibly pathogenic based on PolyPhen-2, SIFT, SNAP and MutationTaster predictions (4/4 predictions against neutrality considered as pathogenic, $3 / 4$ predictions against neutrality considered as possibly pathogenic).

bBased on 1000 genomes database (http://www.1000genomes.org/). EUR MAF from available European populations and Global MAF from all available populations.

'Pairwise differences after corrections in allele frequencies between cases and controls.

dPairwise differences only before corrections in allele frequencies between cases and controls. 
Table 3 Non-associating variants in the WFS 1 gene

\begin{tabular}{|c|c|c|c|c|c|c|c|c|c|c|c|c|}
\hline \multirow[b]{2}{*}{ Variant } & \multirow[b]{2}{*}{$\begin{array}{l}\text { Amino acid } \\
\text { change }\end{array}$} & \multirow{2}{*}{$\begin{array}{c}\text { EUR MAF } \\
\text { (Global MAF) }\end{array}$} & \multicolumn{2}{|c|}{ Controls $(\mathrm{N}=285)$} & \multicolumn{2}{|c|}{$D M(\mathrm{~N}=182)$} & \multicolumn{2}{|c|}{$S N H I(N=117)$} & \multicolumn{2}{|c|}{$O A(\mathrm{~N}=44)$} & \multicolumn{2}{|c|}{$S V(\mathrm{~N}=95)$} \\
\hline & & & $\mathrm{N}$ & Allele freq. & $\mathrm{N}$ & Allele freq. & $\mathrm{N}$ & Allele freq. & $\mathrm{N}$ & Allele freq. & $\mathrm{N}$ & Allele freq \\
\hline \multicolumn{13}{|l|}{ Rs-code } \\
\hline rs56072215 & - & $0.053(0.028)$ & 6 & 0.0123 & 5 & 0.0137 & 7 & 0.0299 & 0 & & 5 & 0.0263 \\
\hline rs71539646 & - & $0.007(0.003)$ & 2 & 0.0035 & 4 & 0.0110 & 3 & 0.0128 & 2 & 0.0227 & 3 & 0.0158 \\
\hline rs2230719 & - & $0.053(0.042)$ & 6 & 0.0123 & 5 & 0.0137 & 7 & 0.0299 & 0 & & 5 & 0.0263 \\
\hline rs1805070 & Ile720Val & $0.009(0.019)$ & 11 & 0.0193 & 4 & 0.0110 & 10 & 0.0427 & 1 & 0.0114 & 5 & 0.0263 \\
\hline rs1805070 & Ile720Leu & N.D. & 3 & 0.0053 & 0 & & 0 & & 0 & & 1 & 0.0053 \\
\hline rs71530908 & - & $0.007(0.002)$ & 5 & 0.0088 & 0 & & 0 & & 0 & & 1 & 0.0053 \\
\hline rs71532871 & Val871Met & $0.009(0.004)$ & 7 & 0.0123 & 9 & 0.0247 & 4 & 0.0171 & 0 & & 1 & 0.0053 \\
\hline
\end{tabular}

Abbreviations: DM, diabetes mellitus; EUR MAF, European minimum allele frequency; Global MAF, global minimum allele frequency; N.D., not determined; OA, optic atrophy; SNHI, sensorineural hearing impairment; SV, suicide victim.

a None of the three nonsynonymous variants were predicted as pathogenic or possibly pathogenic based on PolyPhen-2, SIFT, SNAP and MutationTaster predictions (4/4 predictions against neutrality considered as pathogenic, $3 / 4$ predictions against neutrality considered as possibly pathogenic).

${ }^{\mathrm{b} B a s e d}$ on 1000 genomes database (http://www.1000genomes.org/). EUR MAF from available European populations and Global MAF from all available populations.

\section{Frequency of affected first-degree relatives among patients with DM and among patients with SNHI}

The two groups of patients with DM $(N=481)$ were combined. Fifty-nine patients harboring the p.[His456] allele were excluded, because the p.[His611] allele and the p.[His456] allele were both associated with DM and because they were estimated to occur in separate haplotypes. In addition, eight patients were excluded because of missing family history information. Then the proportion of probands reporting a first-degree relative with DM was examined among those who harbored one or two alleles of p.[His611] or two reference alleles (Figure 3 ). The differences were not significant between genotypes $(P=0.66$; between homozygotes $P=0.23)$. However, a trend-wise increase of positive family history was present in the patients who were heterozygotes or homozygotes with respect to the p.[His611].

A similar analysis among patients with SNHI, who were heterozygotes with respect to p.Arg456His, did not reveal differences in the frequency of positive family history with respect to SNHI. The p.[His456] allele homozygotes were not analyzed because of their small number.

\section{DISCUSSION}

\section{Two WFS1 variants are associated with DM and SNHI}

We found that the frequency of the p.[His456] allele was higher in patients with DM, who had started insulin therapy between the ages 20 and 45 years, than that in the controls. Previously, it has been found that the frequency of the p.[His456] allele is higher in patients with type $1 \mathrm{DM}$ than that in controls. ${ }^{27} \mathrm{~A}$ recent large-scale study recommends further investigations of p.Arg456His in the patients with type II DM. ${ }^{53}$ We also observed an association between the p.[His611] allele and DM, supporting previous studies..$^{21,24-26}$ The increase in the allele frequencies could be observed in two independent cohorts of patients with DM. Furthermore, we pointed out that patients with DM, who were homozygotes or heterozygotes with respect to p.[His611], reported slightly more often first-degree relatives affected with DM than patients who were homozygotes with respect to the reference. This finding, however, needs to be substantiated in larger patient cohorts. These findings further support the hypothesis that the p.Arg611His variant is a risk factor for DM. Previous studies have shown a highly significant association between the rs10010131 variant and $\mathrm{DM}, 23,24,54,55$ but we did not detect such an association. In addition to DM, we found association between the p.[His456] allele

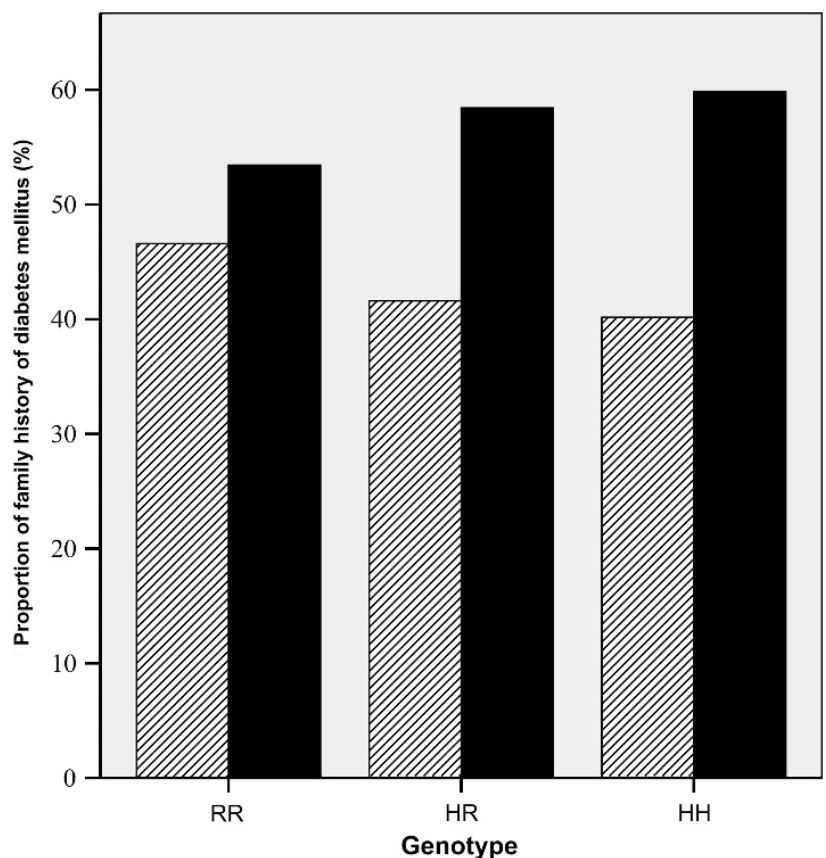

Figure 3 Proportion of patients with DM $(N=414)$ reporting family history of DM in first-degree relatives. Solid columns, DM patients with first-degree relatives with DM. Striped columns, DM patients with no first-degree relatives with DM. RR, patients homozygous with respect to p.[Arg611] allele $(N=73) ; \mathrm{RH}$, patients heterozygotes with respect to p.[Arg611] and p.[His611] alleles $(N=214) ; H H$, patients homozygous with respect to p.[His611] allele $(N=127)$.

and SNHI and OA, respectively. The association of WFS1 variants with hearing impairment has been shown previously, ${ }^{20,22,28-31}$ but this is the first report where the p.[His456] allele is found to be associated with an increased risk of SNHI.

Depression and other psychiatric findings are common in $\mathrm{WS}^{3}$ and, in addition, WFS1 knockout mice show depression-like phenotype in behavioral tests. ${ }^{16}$ In line with these findings, previous studies have described an association between p.Arg611His and suicide, ${ }^{33,34}$ but we could not confirm this association. The SVs were incident cases occurring in a specific period of time, whereas the other patient 
groups were prevalent cases. However, it is unlikely that the method of case finding influences the results. The factors behind suicidal behavior are heterogenic and, therefore, genetic associations are either difficult to recognize or the identified associations could be biased.

Our sample size was only modest but, even so, we could confirm an association between certain WFS1 variants and SNHI and DM, respectively, in Finnish patients. Finns differ from Swedes, British and Germans, and, in addition, the within-population difference between Eastern Finns and Western Finns is greater than the difference between Germans and British. ${ }^{56}$ Population structure could have a remarkable function in large, multicenter association studies. ${ }^{57}$ Because of such differences, it is important to identify genetic variation in different ethnic groups, including populations, where the attainable sample size may remain small.

\section{Rare heterozygous variants in WFS1}

Two novel nonsynonymous variants were found in the patients but not in the controls (Figure 2). The p.Asp389Ala variant was found in a patient with SNHI, who did not report other health problems. An unaffected sibling of the patient was a carrier of p.[Ala389], suggesting that a single copy of this allele alone does not explain the clinical phenotype of the patient with SNHI. The p.Glu403Asp variant was found in two patients, one of whom had SNHI and DM. This patient had three siblings and mother with hearing impairment. Interestingly, the affected sister had the heterozygous p.Glu403Asp variant, whereas the unaffected brother had two reference alleles. However, more samples from the relatives should be genotyped to investigate possible pathogenicity of the variant. The other patient with p.Glu403Asp had DM, hearing impairment and impaired vision, as well as memory problems. Unfortunately, further investigation on this family was not possible. The change from aspartic acid to alanine is a nonconservative one, whereas the change from glutamic acid to aspartic acid is a conservative one. Despite the lack of clear evidence of pathogenicity, four algorithms predicted the variants p.Asp389Ala and p.Glu403Asp to be pathogenic.

Furthermore, five previously reported rare variants were found in the patients but not in the controls (Figure 2). The p.Glu385Lys variant was found in a patient with OA and in a patient with SNHI. The patient with OA had had epilepsy in her childhood, whereas the patient with SNHI was otherwise healthy. This variant has previously been described as a polymorphism, ${ }^{58}$ but was predicted to be possibly pathogenic in our study. We found the p.Ala559Thr variant in an SV and in two patients with DM free from other health problems. This variant has been suggested to be related to psychiatric disorders ${ }^{32,59}$ and, furthermore, this variant has been found in a patient with WS in heterozygous form. ${ }^{60}$ The contribution of the p.Ala559Thr remains unclear, however, as the WS patient was a compound heterozygote for an in-frame deletion and a frameshift insertion in cis with p.Ala559Thr. In addition, the variant has been found in patients with DM, and also in their unaffected relatives. ${ }^{61}$ Predictions of pathogenicity suggested p.Ala559Thr to be a polymorphism. The third previously described rare variant, p.Arg818Cys, was found in two patients with DM free from other health problems. This variant has been found in psychiatric patients ${ }^{62}$ and in homozygous form in two Spanish WS patients. ${ }^{63}$ However, these WS patients were homozygotes also with respect to the p.Glu737Lys mutation in WFS1 and, in addition, they had a possibly pathogenic point mutation and multiple deletions in their mitochondrial DNA. It has been suggested that p.Arg818Cys is a polymorphism. ${ }^{30}$ The p.Arg756Cys variant was found in a patient with SNHI, whose mother had hearing impairment, and in an SV. This variant was found in the single-nucleotide polymorphism database of the National Institute of Biotechnology Information (http:// www.ncbi.nlm.nih.gov/projects/SNP/), but no functional data are available. Both p.Arg756Cys and p.Arg818Cys were predicted to be pathogenic. In our study, however, the functional role of these six variants remains unclear because of the heterozygosity and rarity of the variants. Interestingly, each of these six rare amino acid variants occurred in a more conserved segment of the wolframin protein than the p.Arg456His and p.Arg611His variants (Supplementary File S1). The last previously described rare variant was the nonsense mutation p.Gln667*, which was found in one SV. This mutation has been previously found in three WS patients, whose symptoms did not include psychiatric findings. ${ }^{17,64}$ Heterozygotes of WS mutations have been estimated to require 26-fold more likely psychiatric hospitalization. ${ }^{19}$

In conclusion, we suggest that p.Arg456His and p.Arg611His variants of WFS1 carry an increased risk of DM and SNHI. These variants may be harmful by themselves, be markers for linked harmful mutations or their effect could be additive to other genetic factors.

\section{ACKNOWLEDGEMENTS}

We thank Ms Pirjo Keränen and Ms Anja Heikkinen for their expert technical assistance. This work was supported in part by grants from the Academy of Finland (project numbers 107174 and 127764) and from the Sigrid Juselius Foundation.

1 Wolfram, D. J. \& Wagener, H. P. Diabetes mellitus and simple optic atrophy among siblings: report of four cases. Mayo Clin. Proc. 13, 715-718 (1938).

2 Dreyer, M., Rüdiger, H. W., Bujara, K., Herberhold, C., Kühnau, J., Maack, P. et al. The syndrome of diabetes insipidus, diabetes mellitus, optic atrophy, deafness and other abnormalities (DIDMOAD-syndrome). Klin. Wochenschr. 60, 471-475 (1982).

3 Swift, R. G., Sadler, D. B. \& Swift, M. Psychiatric findings in Wolfram syndrome homozygotes. Lancet 336, 667-669 (1990).

4 Barrett, T. G., Bundey, S. E. \& Macleod, A. F. Neurodegeneration and diabetes: UK nationwide study of Wolfram (DIDMOAD) syndrome. Lancet 346, 1458-1463 (1995).

5 Fraser, F. C. \& Gunn, T. Diabetes mellitus, diabetes insipidus and optic atrophy. An autosomal recessive syndrome? J. Med. Genet. 14, 190-193 (1977).

6 Inoue, H., Tanizawa, Y., Wasson, J., Behn, P., Kalidas, K., Bernal-Mizrachi, E. et al. A gene encoding a transmembrane protein is mutated in patients with diabetes mellitus and optic atrophy (Wolfram syndrome). Nat. Genet. 20, 143-148 (1998).

7 Strom, T. M., Hörtnagel, K., Hofmann, S., Gekeler, F., Scharfe, C., Rabl, W. et al. Diabetes insipidus, diabetes mellitus, optic atrophy and deafness (DIDMOAD) caused by mutations in a novel gene (wolframin) coding for a predicted transmembrane protein. Hum. Mol. Genet. 7, 2021-2028 (1998).

8 Takeda, K., Inoue, H., Tanizawa, Y., Matsuzaki, Y., Oba, J., Watanabe, Y. et al. WFS1 (Wolfram syndrome 1) gene product: predominant subcellular localization to endoplasmic reticulum in cultured cells and neuronal expression in rat brain. Hum. Mol. Genet. 10, 477-484 (2001).

9 Hofmann, S., Philbrook, C., Gerbitz, K.-D. \& Bauer, M. F. Wolfram syndrome: structural and functional analyses of mutant and wild-type wolframin, the WFS1 gene product. Hum. Mol. Genet. 12, 2003-2012 (2003)

10 Takei, D., Ishihara, H., Yamaguchi, S., Yamada, T., Tamura, A., Katagiri, H. et al. WFS1 protein modulates the free $\mathrm{Ca} 2+$ concentration in the endoplasmic reticulum. FEBS Lett. 580, 5635-5640 (2006).

11 Fonseca, S. G., Ishigaki, S., Oslowski, C. M., Lu, S., Lipson, K. L., Ghosh, R. et al. Wolfram syndrome 1 gene negatively regulates ER stress signaling in rodent and human cells. J. Clin. Invest. 120, 744-755 (2010).

12 Ishihara, H., Takeda, S., Tamura, A., Takahashi, R., Yamaguchi, S., Takei, D. et al. Disruption of the WFS1 gene in mice causes progressive $\beta$-cell loss and impaired stimulus-secretion coupling in insulin secretion. Hum. Mol. Genet. 13, 1159-1170 (2004).

13 Kõks, S., Planken, A., Luuk, H. \& Vasar, E. Cat odour exposure increases the expression of wolframin gene in the amygdaloid area of rat. Neurosci. Lett. 322, 116-120 (2002).

14 Kesner, Y., Zohar, J., Merenlender, A., Gispan, I., Shalit, F. \& Yadid, G. WFS1 gene as a putative biomarker for development of post-traumatic syndrome in an animal models. Mol. Psychiatr. 14, 86-94 (2009).

15 Luuk, H., Plaas, M., Raud, S., Innos, J., Sütt, S., Lasner, H. et al. Wfs1-deficient mice display impaired behavioural adaptation in stressful environment. Behav. Brain Res. 198, 334-345 (2009) 
16 Kato, T., Ishiwata, M., Yamada, K., Kasahara, T., Kakiuchi, C., Iwamoto, K. et al. Behavioral and gene expression analyses of WFS1 knockout mice as a possible animal model of mood disorder. Neurosci. Res. 61, 143-158 (2008).

17 Hardy, C., Khanim, F., Torres, R., Scott-Brown, M., Seller, A., Poulton, J. et al. Clinical and molecular analysis of 19 Wolfram syndrome kindreds demonstrating a wide spectrum of mutations in WFS1. Am. J. Hum. Genet. 65, 1279-1290 (1999).

18 Hofmann, S. \& Bauer, M. F. Wolfram syndrome-associated mutations lead to instability and proteasomal degradation of wolframin. FEBS Lett. 580, 4000-4004 (2006).

19 Swift, R. G., Polymeropoulos, M. H., Torres, R. \& Swift, M. Predisposition of Wolfram syndrome heterozygotes to psychiatric illness. Mol. Psychiatr. 3, 86-91 (1998).

20 Ohata, T., Koizumi, A., Kayo, T., Shoji, Y., Watanabe, A., Monoh, K. et al. Evidence of an increased risk of hearing loss in heterozygous carriers in a Wolfram syndrome family. Hum. Genet. 103, 470-474 (1998).

21 Minton, J. A., Hattersley, A. T., Owen, K., McCarthy, M. I., Walker, M., Latif, F. et al. Association studies of genetic variation in the WFS1 gene and type 2 diabetes in U.K. populations. Diabetes 51, 1287-1290 (2002).

22 Domènech, E., Gómez-Zaera, M. \& Nunes, V. WFS1 mutations in Spanish patient with diabetes mellitus and deafness. Eur. J. Hum. Genet. 10, 421-426 (2002)

23 Sandhu, M. S., Weedon, M. N., Fawcett, K. A., Wasson, J., Debenham, S. L. \& Daly, A. Common variants in WFS1 confer risk of type 2 diabetes. Nat. Genet. 39, 951-953 (2007)

24 Franks, P. W., Rolandsson, O., Debenham, S. L., Fawcett, K. A., Payne, F., Dina, C. et al. Replication of the association between variants in WFS1 and risk of type 2 diabetes in European populations. Diabetologia 51, 458-463 (2008).

25 Spars $\varnothing$, T., Andersen, G., Albrechtsen, A., Jørgensen, T., Borch-Johnsen, K., Sandbaek, A. et al. Impact of polymorphisms in WFS1 on prediabetic phenotypes in a populationbased sample of middle-aged people with normal and abnormal glucose regulation. Diabetologia 51, 1646-1652 (2008).

26 Cheurfa, N., Brenner, G. M., Reis, A. F., Dubois-Laforgue, D., Roussel, R., Tichet, J. et al. Decreased insulin secretion and increased risk of type 2 diabetes associated with allelic variations of the WFS1gene: the Data from Epidemiological Study on the Insulin Resistance Syndrome (DESIR) prospective study. Diabetologia 54 554-562 (2011)

27 Awata, T., Inoue, K., Kurihara, S., Ohkubo, T., Inoue, I., Abe, T. et al. Missense variations of the gene responsible for Wolfram syndrome (WFS1/wolframin) in Japanese: Possible contribution of Arg456His mutation to type 1 diabetes as a nonautoimmune genetic basis. Biochem. Biophys. Res. Commun. 268, 612-616 (2000)

28 Young, T. L., Ives, E., Lynch, E., Person, R., Snook, S., MacLaren, L. et al. Non-syndromic progressive hearing loss DFNA38 is caused by heterozygous missense mutation in the Wolfram syndrome gene WFS1. Hum. Mol. Genet. 10, 2509-2514 (2001)

29 Bespalova, I. N., Van Camp, G., Bom, S. J., Brown, D. J., Cryns, K., DeWan, A. T. et al. Mutations in the Wolfram syndrome 1 gene (WFS1) are a common cause of low frequency sensorineural hearing loss. Hum. Mol. Genet. 10, 2501-2508 (2001).

30 Cryns, K., Pfister, M., Pennings, R. J., Bom, S. J., Flothmann, K., Caethoven, G. et al. Mutations in the WFS1 gene that cause low-frequency sensorineural hearing loss are small non-inactivating mutations. Hum. Genet. 110, 389-394 (2002)

31 Fukuoka, H., Kanda, Y., Ohta, S. \& Usami, S. Mutations in the WFS1 gene are a frequent cause of autosomal dominant nonsyndromic low-frequency hearing loss in Japanese. J. Hum. Genet. 52, 510-515 (2007)

32 Furlong, R. A., Ho, L. W., Rubinsztein, J. S., Michael, A., Walsh, C., Paykel, E. S. et al A rare coding variant within the wolframin gene in bipolar and unipolar affective disorder cases. Neurosci. Lett. 277, 123-126 (1999).

33 Sequeira, A., Kim, C., Seguin, M., Lesage, A., Chawky, N., Desautels, A. et al. Wolfram syndrome and suicide: evidence for a role of WFS1 in suicidal and impulsive behavior. Am. J. Med. Genet. B Neuropsychiatr. Genet. 119B, 108-113 (2003).

34 Must, A., Kõks, S., Vasar, E., Tasa, G., Lang, A., Maron, E. et al. Common variations in $4 p$ locus are related to male completed suicide. Neuromol. Med. 11, 13-19 (2009).

35 Zalsman, G., Mann, M. J., Huang, Y. Y., Oquendo, M. A., Brent, D. A. Burke, A. K. et al. Wolframin gene H611R polymorphism: No direct association with suicidal behavior but possible link to mood disorders. Prog. Neuropsychopharmacol. Biol. Psychiatr. 33, 707-710 (2009).

36 Majamaa, K., Moilanen, J. S., Uimonen, S., Remes, A. M., Salmela, P. I., Kärppä, M. et al. Epidemiology of A3243G, the mutation for mitochondrial encephalomyopathy, lactic acidosis, and strokelike episodes: Prevalence of the mutation in an adult population. Am. J. Hum. Genet. 63, 447-454 (1998).

37 Lehtonen, M. S., Uimonen, S., Hassinen, I. E. \& Majamaa, K. Frequency of mitochondrial DNA point mutations among patients with familial sensorineural hearing impairment. Eur. J. Hum. Genet. 8, 315-318 (2000).

38 Remes, A. M., Kärppä, M., Moilanen, J. S., Rusanen, H., Hassinen, I. E., Majamaa, K. et al. Epidemiology of the mitochondrial DNA 8344A $>\mathrm{G}$ mutation for the myoclonus epilepsy and ragged red fibres (MERRF) syndrome. J. Neurol. Neurosurg. Psychiatr. 74 1157-1159 (2003).
39 Martikainen, M. H., Rönnemaa, T. \& Majamaa, K. Prevalence of mitochondrial diabetes in southwestern Finland: a molecular epidemiological study. Acta Diabetol. doi:10.1007/s00592-012-0393-2 (2012).

40 Körkkö, J., Annunen, S., Pihlajamaa, T., Prockop, D. \& Ala-Kokko, L. Conformation sensitive gel electrophoresis for simple and accurate detection of mutations Comparison with denaturing gradient gel electrophoresis and nucleotide sequencing. Proc. Natl Acad. Sci. USA 95, 1681-1685 (1998)

41 Guo, S. W. \& Thompson, E. A. Performing the exact test of Hardy-Weinberg proportion for multiple alleles. Biometrics 48, 361-372 (1992).

42 Raymond, M. \& Rousset, F. An exact test for population differentiation. Evolution 49, 1280-1283 (1995).

43 Excoffier, L. \& Lischer, H. Arlequin suite ver 3.5: a new series of programs to perform population genetics analyses under Linux and Windows. Mol. Ecol. Resour. 10, 564-567 (2010)

44 Benjamini, Y. \& Hochberg, Y. Controlling the false discovery rate: A practical and powerful approach to multiple testing. J. R. Stat. Soc. Series. B Stat. Methodol. 57 , 289-300 (1995)

45 Everitt, B. S. The Analysis of Contingency Tables (Chapman and Hall Ltd, London, 1977).

46 Adzhubei, I. A., Schmidt, S., Peshkin, L., Ramensky, V. E., Gerasimova, A., Bork, P. et al. A method and server for predicting damaging missense mutations. Nat. Methods 7, 248-249 (2010).

$47 \mathrm{Ng}$, P. C. \& Henikoff, S. Predicting deleterious amino acid substitutions. Genome Res. $11,863-874$ (2001).

48 Bromberg, Y. \& Rost, B. SNAP: predict effect of non-synonymous polymorphisms on function. Nucleic Acids Res. 35, 3823-3835 (2007).

49 Schwarz, J. M., Rödelsperger, C., Schuelke, M. \& Seelow, D. MutationTaster evaluates disease-causing potential of sequence alterations. Nat. Methods 7, 575-576 (2010).

50 Sievers, F., Wilm, A., Dineen, D., Gibson, T. J., Karplus, K., Li, W. et al. Fast, scalable generation of high-quality protein multiple sequence alignments using Clustal Omega. Mol. Syst. Biol. 7, 539 (2011).

51 Goujon, M., McWilliam, H., Li, W., Valentin, F., Squizzato, S., Paern, J. et al. A new bioinformatics analysis tools framework at EMBL-EBI (2010). Nucleic Acids Res. 38 (Web Server issue), W695-W699 (2010).

52 Krogh, A., Larsson, B., von Heijne, G. \& Sonnhammer, E. L. Predicting transmembrane protein topology with a hidden markov model: application to complete genomes. J. Mol. Biol. 305, 567-580 (2001)

53 Saxena, R., Elbers, C. C., Guo, Y., Peter, I., Gaunt, T. R., Mega, J. L. et al. Large-scale gene-centric meta-analysis across 39 studies identifies type 2 diabetes loci. Am. J. Hum. Genet. 90, 410-425 (2012).

54 Schäfer, S. A., Müssig, K., Staiger, H., Machicao, F., Stefan, N., Gallwitz, B. et al. A common genetic variant in WFS1 determines impaired glucagon-like peptide-1 induced insulin secretion. Diabetologia 52, 1075-1082 (2009)

55 Fawcett, K. A., Wheeler, E., Morris, A. P., Ricketts, S. L., Hallmans, G., Rolandsson, 0. et al. Detailed investigation of the role of common and low-frequency WFS1 variants in type 2 diabetes risk. Diabetes 59, 741-746 (2010).

56 Salmela, E., Lappalainen, T., Fransson, I., Andersen, P. M., Dahlman-Wright, K., Fiebig, A. et al. Genome-wide analysis of single nucleotide polymorphisms uncovers population structure in Northern Europe. PLOS ONE 3, e3519 (2008).

57 Marchini, J., Cardon, L. R., Phillips, M. S. \& Donnelly, P. The effects of human population structure on large genetic association studies. Nat. Genet. 36, 512-517 (2004).

58 Cryns, K., Sivakumaran, T. A., Van den Ouweland, J. M., Pennings, R. J., Cremers, C W., Flothmann, K. et al. Mutational spectrum of the WFS1 gene in Wolfram syndrome nonsyndromic hearing impairment, diabetes mellitus, and psychiatric disease. Hum. Mutat. 22, 275-287 (2003).

59 Crawford, J., Zielinski, M. A., Fisher, L. J., Sutherland, G. R. \& Goldney, R. D. Is there relationship between Wolfram syndrome carrier status and suicide? Am. J. Med. Genet. 114, 343-346 (2002).

60 Eller, P., Föger, B., Gander, R., Sauper, T., Lechleitner, M., Finkenstedt, G. et al. Wolfram syndrome: a clinical and molecular genetic analysis. J. Med. Genet. 38, e37 (2001).

61 Larsen, Z. M., Johannesen, J., Kristiansen, O. P., Nerup, J., Pociot, F. et al. Danish IDDM Epidemiology and Genetics Group. Evidence for linkage on chromosome 4p16.1 in type 1 diabetes Danish families and complete mutation scanning of the WFS (Wolframin) gene. Diabet. Med. 21, 218-222 (2004).

62 Torres, R., Leroy, E., Hu, X., Katrivanou, A., Gourzis, P., Papachatzopoulou, A. et al. Mutation screening of the Wolfram syndrome gene in psychiatric patients. Mol. Psychiatr. 6, 39-43 (2001).

63 Gómez-Zaera, M., Strom, T. M., Rodriguez, B., Estivill, X., Meitinger, T. \& Nunes, V. Presence of a major WFS1 mutation in Spanish Wolfram syndrome pedigrees. Mol. Genet. Metab. 72, 72-81 (2001).

64 Mathis, S., Maisonabe, T. \& Neau, J. P. Neuropathy in Wolfram syndrome. Eur. J. Med. Genet. 54, 73-75 (2011).

Supplementary Information accompanies the paper on Journal of Human Genetics website (http://www.nature.com/jhg) 